\title{
Research of University Ecological Civilization Education
}

\author{
Yan Liu \\ School of Marxism \\ Northeast Dianli University \\ Jinlin, China
}

\begin{abstract}
This article is based on the concept of ecological civilization education and the theoretical basis and Cultural Origins analysis, It discusses the necessity of ecological civilization education in colleges and universities, and to study ways of ecological civilization education in colleges and universities.
\end{abstract}

\section{Keywords-ecological civilization; education; research}

\section{INTRODUCTION}

Ecological civilization consists of two nouns "ecological" and "civilization", It refers to human understanding of the black economy and reflecting industrial civilization, and explorating the new theory of a sustainable development. It is external representation of civilized social ecology; it also is a new understanding of the human about development model and way. It is the basis of following the development of human history and the nature of the variation, It is based on respect for and protection of nature as a precondition, It is based on scientific development and harmonious coexistence with the goal, It is proper coordination good relationship with human and nature, survival and development in practice.

\section{RELATED CONCEPTS AND THEORETICAL BASIS}

Ecological civilization education is under the guidance of the scientific concept of development, ecology of knowledge as the main content through a variety of media tools to help people understand the ecological problems, develop ecological awareness, establish the correct ecological values, form good habits, so that consciously abide by its laws governing the operation of the natural ecosystem processes. Ecological civilization education has its own uniqueness: Covering a broader and diverse forms of communication, more emphasis on practice. Ecological Civilization Education of College takes the harmonious development of man and nature as a starting point, according to the educational goals of students and group identity, using reasonable means of education, student groups to impose a planned, purposeful, systematic education to help them deal with man and nature Relationship.

Ecological Civilization Education of College has a solid theoretical foundation and cultural origin. Marxist concept of ecological civilization, the concept of Chinese Traditional Ecological Ethics and scientific development of ecological civilization Ecological laid the theoretical foundation of
Civilization Education of College. Marx and Engels always been concerned about the relationship between man and nature, their ecological thought provides both direct sources for the contemporary theory of ecological view of nature, pointed out the direction of educational research and practice of ecological civilization College. Marx said: "People create an environment, the same environment also created man."'[1] Nature is fundamental and basic of human survival and development, provide adequate material conditions of human existence. Man and nature are unified in essence, people can not survive away from nature, human beings must respect nature, protect nature, and otherwise it will lead to disaster. As Marx said, the capitalist mode of production unlimited pursuit of profit, lead to a variety of natural resources have been obtained with the use of uncontrolled, and thus beyond the carrying capacity of nature. The key to solving ecological problems lies in accordance with natural laws, rationally regulate the relationship between man and nature. Marx pay particular attention to Recycling and resource conservation significance, actively promote green consumption, that the material consumption can not exceed the speed of economic development, it can not affect the quality of the environment, but should coordinate with them. Marx and Engels argued that technological innovations can effectively improve production tools and processing industries, and to minimize unwarranted consumption of resources in production, so that the original scarce materials for more efficient use, reducing the pressure on the ecological environment .A long history of traditional Chinese culture, contains rich ecological Ethics. These ideas are the fruits of development of human ecological civilization, provides an important reference for ecological civilization education in contemporary colleges and universities Confucianism advocates "Heaven", "all things equal", "moderate" way. Taoism advocates "nature" and "quietism" Ecological View. Buddhist respected "karma harmony", "everyone is equal" ecological concept, traditional culture ecology concept for today's ecological civilization construction provides a strong theoretical support. today's society , Overall progress and harmonious development of the pursuit of scientific development, and ecological civilization within the expected generation of justice, intergenerational justice is essentially the same, which determines the construction of ecological civilization taking the scientific outlook on development as guidance, "Construction of ecological civilization needs to leading and pushing role of education, In the whole society 
to form ecological civilization values and the correct production, life and consumption behavior.'[2]

\section{NECESSITY OF ECOLOGICAL CIVILIZATION EDUCATION IN COLLEGES AND UNIVERSITIES}

Continuing to strengthen ecological civilization education of college students is not only the inevitable trend of historical development, but also an important choice human values change. Therefore, the exploration of ecological civilization education for College Students imperative. The party's 18th report makes clear that"the fully implement economic construction, political construction, cultural construction, social construction, ecological civilization one of five overall layout" [3] And, in special sections devoting ecological civilization, it said: "the construction of ecological civilization, is about the welfare of the people and about the nation's future long-term plan.'[3] Universities have a unique talent, resources and cultural advantages, but also to promote the mission and tasks of human civilization and the progress, ecological civilization education in universities is an inevitable demand of the times. Ecological civilization education appeal to the young students to protect the natural, care for the environment, maximizing creativity on the basis of following ecological laws. Humans have responsibility to protect nature in process of the transformation of the nature, but also pay more attention to balance and harmony between man and nature, in line with the requirements of the Contemporary Moral Development. Ecological Civilization Education of College Contained ecological ethics and ecological ethics, the moral category has been expanded to become an important part of contemporary moral education, to further promote the development of moral education. College ecological civilization Education requirements Students in a holistic perspective to understand the relationship between man and nature, education of college students should be based on long-term interests, respect for nature, fulfill ecological responsibility. Students on basis of long-term interests, respect for nature and fulfill ecological responsibility. Ecological Civilization Education of College develops the ability of students to regulate the relationship between man and nature, but also to make it better reflect on tradition, seeking to develop a new model of harmony between man and nature, thus contributing to the development of selfcultivation and to enhance the overall quality and comprehensive.

\section{WAY OF ECOLOGICAL CIVILIZATION EDUCATION OF UNIVERSITIES}

Ecological Civilization Education of College must establish a correct concept of ecological education. When humans gradually walking to ecological civilization, education should go beyond goals of industrialization and instrumental, in turn promote the comprehensive development of human, ecological civilization education in universities, takes "eco" as the goal of education, constantly culture and enhance college students' ecological awareness, promote human, natural and social harmony together. Classroom teaching is the main channel of institutions of higher learning education of ecological civilization, so that, building a sound ecological civilization classroom teaching system is imperative. In fact, developing a"human ecology"is the process of realization of the ecological value of education, for exampel, the introduction of ecological civilization education in classroom teaching, cultivating ecological awareness of college students, and establishing their ecological responsibility. Teaching content of ecological civilization in addition to the basics of ecology, but also include eco legal education, ecological economic education and ecological consumption View. However, the ecological civilization education is interdisciplinary and can not be independent from environmental education subjects, so according to the students' original ecological qualities and characteristics of different disciplines to implement ecological civilization education. In 2003, the Ministry of Education said that "all disciplines in special education should be based on the penetration of environmental education." This actually provides direction and support for the education of ecological civilization, to make it easier and more rapid expansion in environmental education basis. Moreover, the implementation of interdisciplinary ecological education has its obvious advantages, just according to the characteristics of the various disciplines, each discipline has little educational content integration, without changing the existing course structure.

IT is necessary to promote ecological civilization education of universities in addition to promoting ecological concept internalization, it is more important to turn ecological ideas into one act through practice .Colleges and universities should increase innovation in the classroom, to explore an effective way of curricular practice teaching, On the one hand, teachers aid multimedia platform, using pictures, videos to design and implement Ecological Civilization Education. Teachers lead Students into a profound reflection on ecological problems through audiovisual data and comparative analysis, and select ecological hotspots examples in class, to stimulate students' thinking in the form of questions. At the same time, using the network transmission speed and rich information resources advantages, seting up the introduction of "ecological civilization" column in the campus site. On the other hand, the ecological civilization education of colleges and universities should be based on reality, do not rigidly adhere to the conventional way of education the concept of ecological civilization is permeated into college students' mind by brainstorming and communicating with in Recessive education. Social practice is the ultimate goal of ecological civilization education in colleges and universities, college students actively participate in social practice to enhance the effectiveness of education through a variety of practical activities, in order to truly comprehend the connotation of ecology and the formation of ecological moral responsibility, and strengthen ecological values. Therefore, the ecological civilization education in universities should be extend into the second class, taking social practice activities as the carrier, and actively opening up the second classroom education of ecological civilization, such as organizing students' participation in environmental issues in the survey, making students in the survey to further 
deepen the concept of ecological civilization education; 'Three rural areas' social practice, led the students to visit the conservation area, close to nature in contact with nature, enhance responsibility of ecological protection;"China High Level Forum on Ecological Civilization - Guangzhou Declaration" initiative:"to become an active advocate of the construction of ecological civilization, enthusiastic advocate and loyal practice Departed."[4] College should encourage Students to do ecological volunteer in their spare time, for example, to serve as botanical gardens narrator, taking the ecological civilization education into ecosystem service activities; participation in the design and creation of environmental awareness slogans and environmental thematic works of art, establish and implement the scientific concept of consumption into their own daily behavior, truly ecological burdens. Ecological Civilization Education Universities carry out ecological practice is how to convert into eco-conscious ethical behavior, to correct previous alienation between man and nature, to achieve a high degree of unity both man and nature.

\section{CONCLUSION}

Campus is an important place of students' learning and life, it is closely linked to ecological civilization education in universities, the cultivation of an ecological emotion, establishing ecological beliefs, cultural practices and ecological development and formation of ecological concept and ecological behavior. So colleges and universities actively create a harmonious culture environment of campus, give full play its implicit educational function to make students initiatively accept ecological civilization education and conscientiously perform their acts of ecological civilization. First, the campus material culture ecology. That is substance member universities should reflect the ecological and cultural heritage, reflecting the educational concept of ecological civilization. Campus planning, architectural style, greening fulfill the concept of harmony, making the university campus became the leafy, design layout reasonable ecological demonstration zone. In short, the campus buildings should use recyclable eco-friendly materials, and insist on resource conservation, sustainable use; design layout of buildings should reflect the connotation of harmony, and focus on some details of campus settings, a fully endow campus grass wood ecological factors. For example, in the design of green logo on street lights, trash cans and billboards, make students monasteries, consciously enhance ecological consciousness. Second, the campus spiritual and cultural ecology. Spiritual culture is the core essence of the campus culture, college should organize and propagate campus culture through multi-channel and multiformat and multi-dimensional, to promote the concept of ecological civilization. For example, the creation of ecological civilization thematic special issue, creating ecological campus slogan, publishing or reproducing in newspaper articles about the ecological civilization, carrying out the great debate about ecological civilization in the school, posting the ecological civilization slogans and pictures. And universities should organize students to participate in activities attract college students such as Ecological Day, make students understand ecological, learn ecology and serve ecology. Create ecological sites with authentic materials and clear picture, show spirit style of contemporary college students respecting for nature, protecting the environment, joining the environmental protection.

\section{REFERENCES}

[1] Marx and Engels Collected Works (Volume 1) [M] Beijing: People's Publishing House, 1995, page 92.

[2] BinWu . Schools should strengthen ecological civilization education [N]. China Education Daily, 2009.

[3] Jintao unswervingly advance along the road of socialism with Chinese characteristics for building a moderately prosperous society in all respects - in Eighteenth National Congress of the Communist Party of China on the report [M] Beijing: People's Publishing House, 2012.

[4] "China High Level Forum on Ecological Civilization - Guangzhou Declaration"initiative - everyone contribute to the construction of ecological civilization [J] Anhui Forestry, 2008. 